\title{
Differences in Relative Bioavailability (BA) of Inhalation Insulin Determined using Insulin and Glucose Levels Following Subcutaneous and Inhalation Administration in Humans
}

\author{
Chyung S. Cook ${ }^{1 *}$, Paul W. Valaitis ${ }^{1}$, Andrew Brugger ${ }^{1}$, Tim Heise ${ }^{2}$, Jerry Gass ${ }^{1}$, Laura Anderson ${ }^{1}$, Janice Troeger ${ }^{1}$, Steve White ${ }^{1}$, Uta \\ Eckers $^{2}$, Leszek Nosek ${ }^{2}$, Klause Rave ${ }^{2}$ and Lutz Heinemann²
}

${ }^{1}$ Baxter Healthcare Corporation, Round Lake, IL, USA

${ }^{2}$ Profil Institute for Metabolic Research, Neuss, Germany

\begin{abstract}
BA may be determined using both plasma concentrations of a drug (pharmacokinetic parameters) and its pharmacological effects (pharmacodynamic parameters). However, the resulting assessments of BA can be substantially different. In a relative BA study $(\mathrm{N}=30) 10 \mathrm{IU}(0.35 \mathrm{mg})$ Actrapid $^{\circledR}$ was administered subcutaneously with comparison to a $6.5 \mathrm{mg}$ dose of recombinant human insulin inhalation powder (RHIIP) administered using the Cyclohaler ${ }^{\mathrm{TM}}$ dry powder inhaler under euglycemic glucose clamp conditions. Relative BA following the inhalation administration compared with the subcutaneous dose was $12.0 \pm 1.8 \%$ and $6.3 \pm 0.6 \%$ when determined using baseline-adjusted insulin and glucose infusion rate (GIR), respectively. To explain the observed differences in BA, a pharmacokinetic-pharmacodynamic model was developed and BAs were predicted at different doses of inhalation insulin with the fixed $10 \mathrm{IU}$ subcutaneous dose. BA predicted for $3.25 \mathrm{mg}$ inhaled insulin and GIR were $12 \%$ and $7.5 \%$, respectively. When the potency of the two insulin formulations was compared, it was shown that Actrapid ${ }^{\circledR}$ was approximately 1.4 times greater than the RHIIP formulation. Furthermore, when AUC values for GIR were normalized based on potency BA predicted for a $3.25 \mathrm{mg}$ RHIIP dose was approximately $11 \%$. Thus, the difference in BA dependent upon insulin and glucose could be explained by the non-linear pharmacokinetic-pharmacodynamic relationship and potency difference between RHIIP and Actrapid ${ }^{\circledR}$.
\end{abstract}

Keywords: Inhalation insulin; Glucose infusion rate; Pharmacokinetic-pharmacodynamic modeling

\section{Introduction}

Insulin has been fundamental in the treatment of diabetes for many years. Injected insulin regimens seek to mimic the natural secretion of insulin by the combination of often one or more injections of long acting insulin to provide basal levels and 2-3 injections of short acting insulin to provide maintenance for pre- and post prandial levels around meals. However, injected insulin regimens have some notable disadvantages, as subcutaneously injected insulin does not mimic the natural state and patients require multiple injects per day. Recently alternative methods for the delivery of insulin have been extensively pursued, among which inhalation has proved to be in the forefront and explored by many companies [1]. Baxter Healthcare (Deerfield, IL) developed Recombinant Human Insulin Inhalation Powder (RHIIP) and conducted a bioavailability study to compare with subcutaneous insulin injection in humans. Relative bioavailability following inhalation of RHIIP compared with subcutaneous (SC) Actrapid ${ }^{\mathbb{B}}$ was substantially different from bioavailability determined using glucose infusion rate. Since this pharmacokinetic-pharmacodynamic relationship is nonlinear, bioavailability determined by pharmacodynamic responses are expected to be different depending upon the dose administered. Thus, the current investigation was undertaken to examine if differences in bioavailability determined by insulin concentrations and glucose infusion rate could be explained by this non-linear pharmacokineticpharmacodynamic relationship.

\section{Materials and Methods}

\section{Insulin potency study in rabbits}

Dose solution: For both Actrapid ${ }^{\circledR}$ and RHIIP studies a standard solution was prepared by diluting 40 USP insulin units of USP Insulin Human Reference Standard, Lot No. I1F270 (RS) in the appropriate volume of diluents in order to achieve final concentrations of 1 or 2 USP units $/ \mathrm{ml}$. The diluent was composed of $1.8 \%(\mathrm{w} / \mathrm{v})$ glycerin and $0.1 \%$ $(\mathrm{w} / \mathrm{v})$ phenol in water adjusted with hydrochloric acid to a $\mathrm{pH}$ of 3.2 [2] Assay solution was prepared using the test article (Actrapid ${ }^{\circledR}$ Lot No. 60701 or RHIIP Lot No. 300G1) according to the procedure described in the United States Pharmacopoeia [3] and the appropriate volume of the previously described diluents to achieve final concentrations of 1 or 2 units $/ \mathrm{mL}$.

Animal study: All studies were conducted in accordance with the Animal Welfare Act, 9 CFR Parts 1,2 and 3 (Code of Federal Regulations, Title 9, 2008). Fifty-six female, New Zealand White rabbits weighing 2.6-3.0 kg (approximately 16 weeks of age) were obtained from Myrtle's Rabbitry, Inc (Thosmson Station TN). Rabbits received water ad libitum, except during dosing, and Hi-Fiber Rabbit LabDiet ${ }^{\mathbb{R}}$ (\#5326 Purina Mills, Arlington Heights, IL) once daily. Animals were fasted for at least $14 \mathrm{~h}$ prior to dosing. Twenty-eight rabbits were randomly assigned to four treatment groups of seven animals/group for Actrapid ${ }^{\circledR}$ and RHIIP groups each. Each rabbit received two SC injections of $0.5 \mathrm{ml}$ of standard solution or assay solution containing 1 IU (Solution 1) or 2 IU (Solution 2), as a series with the first injection

*Corresponding author: Chyung S. Cook, Ph.D., 25212 W. Illinois Route 120 Round Lake, Illinois 60073, Tel: (847) 270-5319; E-mail: chyung_cook@baxter.com

Received August 25, 2011; Accepted October 12, 2011; Published October 14 2011

Citation: Cook CS, Valaitis PW, Brugger A, Heise T, Gass J, et al. (2011) Differences in Relative Bioavailability (BA) of Inhalation Insulin Determined using Insulin and Glucose Levels Following Subcutaneous and Inhalation Administration in Humans. J Bioequiv Availab 3: 198-201. doi:10.4172/jbb.1000085

Copyright: @ 2011 Cook CS, et al. This is an open-access article distributed under the terms of the Creative Commons Attribution License, which permits unrestricted use, distribution, and reproduction in any medium, provided the original author and source are credited. 
Citation: Cook CS, Valaitis PW, Brugger A, Heise T, Gass J, et al. (2011) Differences in Relative Bioavailability (BA) of Inhalation Insulin Determined using Insulin and Glucose Levels Following Subcutaneous and Inhalation Administration in Humans. J Bioequiv Availab 3: $198-201$. doi:10.4172/jbb.1000085

on day 1 and the second injection within 7 days of the first (See Table 1). Blood samples were collected at 1 and $2.5 \mathrm{~h}$ post each injection for glucose analysis.

\section{Clinical study}

This was a single center, open label, randomized, active controlled, two-way crossover study. Thirty non-smoking healthy males (aged 18-40 years) were randomized to achieve 15 subjects who completed each treatment sequence. The study consisted of two study periods with confinement to the clinic. Each period was a minimum of $12 \mathrm{hrs}$ in duration with an interval of $72 \mathrm{hrs}$ to 14 days between dosing. The study protocol was approved by the ethics committee of the physical chamber in North Rhine in Germany and the study was performed according to Good Clinical Practice. Subjects gave written informed consent following explanation of the experimental procedure. Following completion of pre-dose procedures, either Recombinant Human Insulin Inhalation Powder (RHIIP) was administered using Cyclohaler ${ }^{\prime \prime}$ dry powder inhaler or Actrapid ${ }^{\circledR}$ human insulin was injected subcutaneously utilizing standard skin-fold technique. The RHIIP dose (Batch number R-01272-A017-01) was $6.5 \mathrm{mg}$ and the subcutaneous Actrapid $^{\circledR}$ dose was $0.35 \mathrm{mg}$ (Batch number ST60180, $\left.10 \mathrm{IU}\right)$. During each study period an automated euglycemic glucose clamp procedure was performed using the Biostator (glucose-controlled system; mtb $\mathrm{GmbH}$, Lonsee-Luizhausen, Germany) to ensure that blood glucose was maintained at a pre-dose level, and also acted as a surrogate marker for the pharmacodynamic effect of exogenous insulin. In the morning of the study days, the fasting subjects were connected to the Biostator by means of three intravenous catheters. The first catheter was used for continuous blood glucose measurement, the second one was used for glucose infusion ( $20 \%$ glucose in water) and the third was used for blood sampling. Glucose requirements were calculated on the basis of the actual blood glucose concentrations measured by the Biostator on a minute-to-minute basis [4]. Arterialized venous blood samples were taken by the Biostator by placing the subject's left hand in a box warmed to an air temperature of $55^{\circ} \mathrm{C}$. During the glucose clamp procedures an intravenous insulin infusion (10 IU Actrapid ${ }^{\circledR}$ in $50 \mathrm{ml}$ of physiological saline $+1 \mathrm{ml}$ of blood of the subject) was administered at a constant rate of $0.15 \mathrm{mIU} / \mathrm{kg} / \mathrm{min}$ in the same vein as the glucose infusion in order to suppress endogenous insulin secretion. The infusion was initiated 120 minutes prior to inhalation or SC injection of RHIIP or Actrapid $^{\circledR}$, respectively, and continued through the last blood sampling time interval in each treatment period.

Blood samples of $0.5 \mathrm{ml}$ for the determination of blood glucose and of $3 \mathrm{ml}$ for the measurement of serum insulin were taken at scheduled time intervals. Glucose concentrations were measured by a clinical laboratory method (Super GL analyzer; Hitado, Mohnesee-Delecke, Germany). Serum insulin concentrations were measured applying an immunochemiluminometric assay (MLT Research, Cardiff, UK). Details of the experimental procedures were published elsewhere [5].

\section{Pharmacokinetic and pharmacodynamic analysis}

Plasma concentration-time curves and corresponding glucose infusion rate following inhalation insulin administration were simultaneously fit according to a pharmacokinetic-pharmacodynamic model (Figure 1) using the ADAPT software program [6]. The differential equations for the proposed pharmacokinetic model for the inhalation dose and the integrated equation for the pharmacodynamic model are given below.
Serum Insulin:

$$
\frac{d x_{1}}{d t}=-\left(k_{e}+k_{c p}\right) x_{1}+k_{a} x_{2}+k_{p c} x_{3}+r
$$

Where $r$ is the intravenous infusion rate.

SC Injection/Inhalation Site:

$$
\frac{d x_{2}}{d t}=-k_{a} x_{2}
$$

Tissue Compartment:

$$
\frac{d x_{3}}{d t}=k_{c p} x_{1}-k_{p c} x_{3}
$$

Biophase Insulin:

$$
\frac{d x_{4}}{d t}=k_{e o}\left(x_{1} / V-x_{4}\right)
$$
below.

The intergraded equation for the glucose infusion rate is shown

$$
G I R=k_{\text {in }} \cdot\left(1+\frac{E_{\max } \cdot C_{e}\left(I_{S}-I_{S}^{0}\right)}{E C_{50}+C_{e}\left(I_{S}-I_{S}^{0}\right)}\right)
$$

GIR: Glucose infusion rate $(\mathrm{mg} / \mathrm{kg} / \mathrm{min})$

$k_{i n}: \quad$ zero-order rate constant for glucose input $(\mathrm{mg} / \mathrm{kg} / \mathrm{min})$

$E C_{50}:$ insulin concentration at half-maximal effect $(\mathrm{ng} / \mathrm{mL})$

$E_{\text {max }}:$ maximum effect of insulin on GIR $(\mathrm{mg} / \mathrm{kg} / \mathrm{min})$

$I_{s}: \quad$ insulin concentration $(\mathrm{ng} / \mathrm{mL})$

\begin{tabular}{|l|l|l|}
\hline Group & $1^{\text {st }}$ Injection & $2^{\text {nd }}$ Injection \\
\hline 1 & Standard Solution 1 & Standard Solution 2 \\
\hline 2 & Standard Solution 2 & Standard Solution 1 \\
\hline 3 & Assay Solution 1 & Assay Solution 2 \\
\hline 4 & Assay Solution 2 & Assay Solution 1 \\
\hline $\begin{array}{l}\text { Standard or Assay Solution 1 = 1 USP unit insulin/ml for USP insulin or RHIIP } \\
\text { solution } \\
\text { Standard or Assay Solution 2 = 2 USP unit insulin/ml for USP insulin or RHIIP } \\
\text { solution }\end{array}$
\end{tabular}

Table 1: Study design of insulin activity in rabbits.

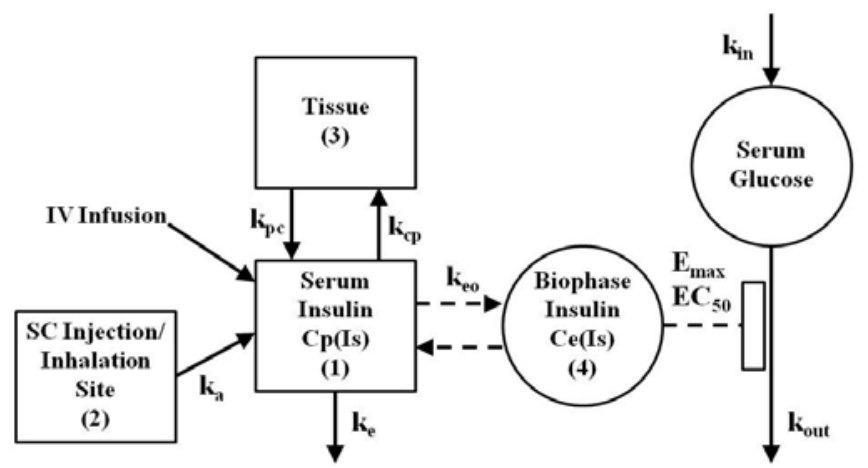

Figure 1: Pharmacokinetic-pharmacodynamic model for insulin. 
Citation: Cook CS, Valaitis PW, Brugger A, Heise T, Gass J, et al. (2011) Differences in Relative Bioavailability (BA) of Inhalation Insulin Determined using Insulin and Glucose Levels Following Subcutaneous and Inhalation Administration in Humans. J Bioequiv Availab 3: $198-201$. doi:10.4172/jbb.1000085

$I_{s}^{0}: \quad$ baseline insulin concentration (before insulin dose, $\mathrm{ng} / \mathrm{mL}$ )

$C_{e}\left(I_{s}-I_{s}^{0}\right): \quad$ Difference between insulin concentration in biophase and insulin baseline in biophase $(\mathrm{ng} / \mathrm{mL})$

After determination of pharmacokinetic and pharmacodynamic parameters with baseline unadjusted insulin concentrations and GIR at the dose of $6.5 \mathrm{mg}$ RHIIP, serum insulin concentrations and GIR for a $3.25 \mathrm{mg}$ RHIIP dose were simulated using the parameters obtained. Then, bioavailability (BA) for insulin and biopotency (BP) for GIR at the $3.25 \mathrm{mg}$ RHIIP dose was calculated as follows:

$$
\mathrm{BA} \text { or } \mathrm{BP}=\frac{\left[\mathrm{AUC}_{\text {ins or GIR }} / \text { Dose }\right]_{\mathrm{RHIIP}}}{\left[\mathrm{AUC}_{\text {ins or GIR }} / \text { Dose }\right]_{\mathrm{SC}}}
$$

$\mathrm{AUC}_{\text {ins or GIR }}$ is baseline adjusted AUC of insulin or GIR, respectively.

\section{Results and Discussion}

Mean serum concentrations of insulin and glucose infusion rate following SC administration of Actrapid ${ }^{\circledR}$ and inhalation of RHIIP are shown in Figure 2 and Figure 3. Table 2 presents baseline subtracted pharmacokinetic parameters of insulin and pharmacodynamic parameters of glucose infusion rates. Following inhalation of RHIIP at the $6.5 \mathrm{mg}$ dose $\mathrm{C}_{\max }$ values were significantly higher, and $\mathrm{T}_{\max }$ values were significantly lower than those following administration of Actrapid $^{\circledR}$ at the $0.35 \mathrm{mg}$ (10 IU) dose. Relative BA of insulin following inhalation of RHIIP was substantially different when determined using glucose infusion rates compared with the BA value

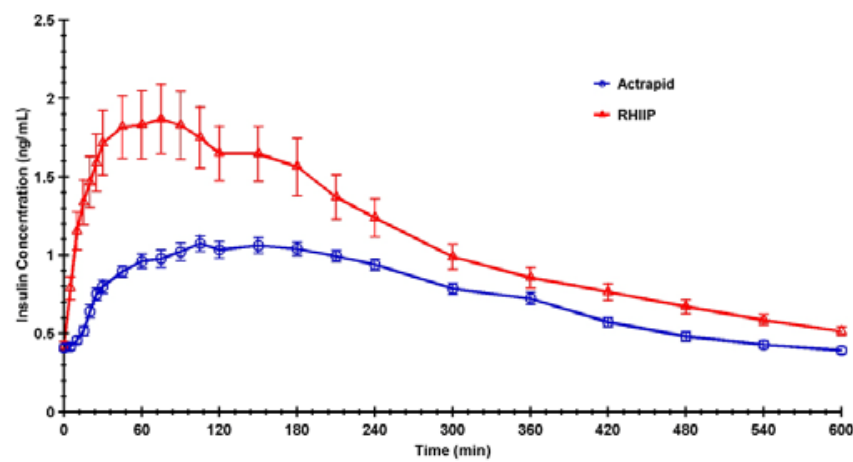

Figure 2: Mean $( \pm S E, N=30)$ baseline unadjusted serum concentrations of insulin following inhalation of RHIIP or subcutaneous administration of Actrapid ${ }^{\circledR}$.

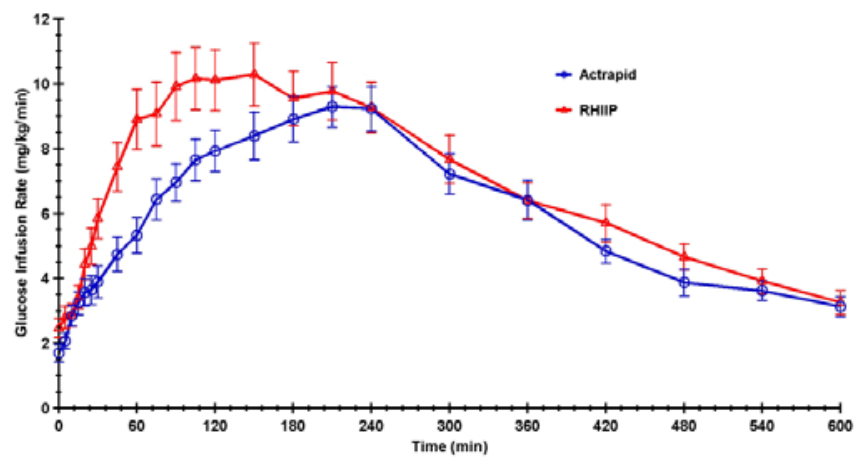

Figure 3: Mean $( \pm S E, N=30)$ baseline unadjusted glucose infusion rate following inhalation of RHIIP or subcutaneous administration of Actrapid ${ }^{\circledR}$.

\begin{tabular}{|c|c|c|c|c|}
\hline \multirow[b]{2}{*}{ PK or PD } & \multirow[b]{2}{*}{ Parameter } & \multicolumn{2}{|c|}{ Mean \pm SE } & \multirow{2}{*}{$\begin{array}{c}P \text { Value } \\
\text { (RHIIP vs } \\
\text { Actrapid }^{\circledR} \text { ) }\end{array}$} \\
\hline & & $\begin{array}{c}\text { RHIIP } \\
(\mathrm{N}=30)\end{array}$ & $\begin{array}{l}\text { Actrapid }^{\circledR} \\
(\mathrm{N}=30)\end{array}$ & \\
\hline \multirow{4}{*}{ PK (Insulin) } & $\mathrm{C}_{\max }(\mathrm{ng} / \mathrm{mL})$ & $1.8 \pm 0.25$ & $0.8 \pm 0.05$ & 0.0006 \\
\hline & $\mathrm{T}_{\max }(\min )$ & $86 \pm 10$ & $141 \pm 12$ & 0.0017 \\
\hline & $\mathrm{AUC}_{(0-10 \mathrm{hr})}(\mathrm{ng} / \mathrm{mL}) \min$ & $411 \pm 57$ & $198 \pm 11$ & 0.0013 \\
\hline & Relative BA (\%) & $12.0 \pm 1.80$ & 100 & $\mathrm{~N} / \mathrm{A}$ \\
\hline \multirow{4}{*}{ PD (GIR) } & $\mathrm{GIR}_{\max }(\mathrm{mg} / \mathrm{kg} / \mathrm{min})$ & $8.4 \pm 0.9$ & $7.6 \pm 0.5$ & 0.3051 \\
\hline & $\mathrm{T}_{\max } \mathrm{GIR}(\min )$ & $173 \pm 13$ & $218 \pm 9$ & $<0.0001$ \\
\hline & $A \cup C_{(0-10 \mathrm{hr})}(\mathrm{mg} / \mathrm{kg})$ & $2734 \pm 274$ & $2482 \pm 155$ & 0.3257 \\
\hline & Relative BP (\%) & $6.3 \pm 0.63$ & 100 & N/A \\
\hline
\end{tabular}

Table 2: Pharmacokinetic (PK) and pharmacodynamic (PD) parameters of insulin (baseline subtracted) following inhalation of RHIIP or subcutaneous administration of Actrapid ${ }^{\circledast}$.

determined using insulin concentrations. These phenomena were also observed in previous studies $[7,8]$. In these studies, BP of inhalation insulin showed a trend towards decreasing as doses for inhalation insulin increased for a given SC dose. The relationship between insulin concentration and glucose responses is sigmoidal and not linear (Hill's equation), and BP determined using glucose responses at high inhalation insulin doses are expected to be lower than those in lower dose ranges. For example in Kim's study [7], where the same insulin was used for both inhalation and SC dose routes, BPs obtained using glucose levels were approximately the same as BAs determined with insulin concentrations at the low inhalation dose (18.9\% BP vs $19.1 \% \mathrm{BA}$ at $80 \mathrm{IU}$ inhalation dose). However, relative BP decreased as the inhalation insulin dose increased and was much lower than BA determined using insulin concentrations (14.3\% BP vs $22.1 \%$ $\mathrm{BA}$ at $240 \mathrm{IU}$ inhalation dose). In order to determine quantitative differences in bioavailability determined by insulin concentrations and glucose infusion rate at different doses of inhalation insulin, a pharmacokinetic-pharmacodynamic model was developed (Figure 1). Several pharmacokinetic-pharmacodynamic models for insulin concentrations and glucose responses were previously reported [911]. The proposed pharmacokinetic-pharmacodynamic model gave a good fit to both the mean insulin concentration-time curve and glucose infusion rate curve following RHIIP inhalation (Figure 4). Obtained pharmacokinetic and pharmacodynamic parameters are given in Table 3. Using these parameters, glucose infusion rates were predicted for the $3.25 \mathrm{mg}$ dose of RHIIP, according to the proposed model, and the AUC of the glucose infusion rate for the $3.25 \mathrm{mg}$ dose was calculated. When relative bioavailability was estimated at the $3.25 \mathrm{mg}$ dose, after normalization based on a mg dose, using the predicted glucose infusion rate the $\mathrm{BP}$ value increased from $6.3 \%$ at the $6.5 \mathrm{mg}$ dose to $7.5 \%$ at the $3.25 \mathrm{mg}$ dose. This predicted BP value was still substantially lower than the BA value determined using insulin concentrations (12\%). When concentrations of insulin were plotted against glucose infusion rate as time sequence, counter clockwise hysteresis was observed for both inhalation of RHIIP and subcutaneous Actrapid ${ }^{\circledR}$ (Figure 5). However, these two curves did not overlap in the same concentration ranges at the same time intervals, thus indicating that the pharmacological response of insulin was different at the same concentration for a given time point (post dose) when RHIIP was given by inhalation and Actrapid $^{\circledR}$ was given subcutaneously. Therefore the potency of RHIIP and Actrapid ${ }^{\circledR}$ was evaluated in a rabbit model. The preliminary 
Citation: Cook CS, Valaitis PW, Brugger A, Heise T, Gass J, et al. (2011) Differences in Relative Bioavailability (BA) of Inhalation Insulin Determined using Insulin and Glucose Levels Following Subcutaneous and Inhalation Administration in Humans. J Bioequiv Availab 3: $198-201$. doi:10.4172/jbb.1000085

results showed that Actrapid ${ }^{\circledR}$ was approximately 1.4 times (28.7 IU/ $\mathrm{mg}$ vs. $21.1 \mathrm{IU} / \mathrm{mg}$ ) more potent than RHIIP on the $\mathrm{mg}$ basis. When $\mathrm{BP}$ was calculated using the glucose infusion rate after normalizing on the basis of potency, it was approximately $8.8 \%$ and $11 \%$ at the 6.5 and $3.25 \mathrm{mg}$ doses, respectively. Thus differences in BA determined by insulin concentrations and BP determined by glucose infusion rate appeared to be due to both a non-linear relationship between insulin concentrations and the glucose response, and also potency differences between RHIIP and Actrapid ${ }^{\circledR}$.

In conclusion the difference in BA of Baxter RHIIP determined by insulin concentrations and BP determined by glucose responses could be explained by the non-linear pharmacokinetic-pharmacodynamic
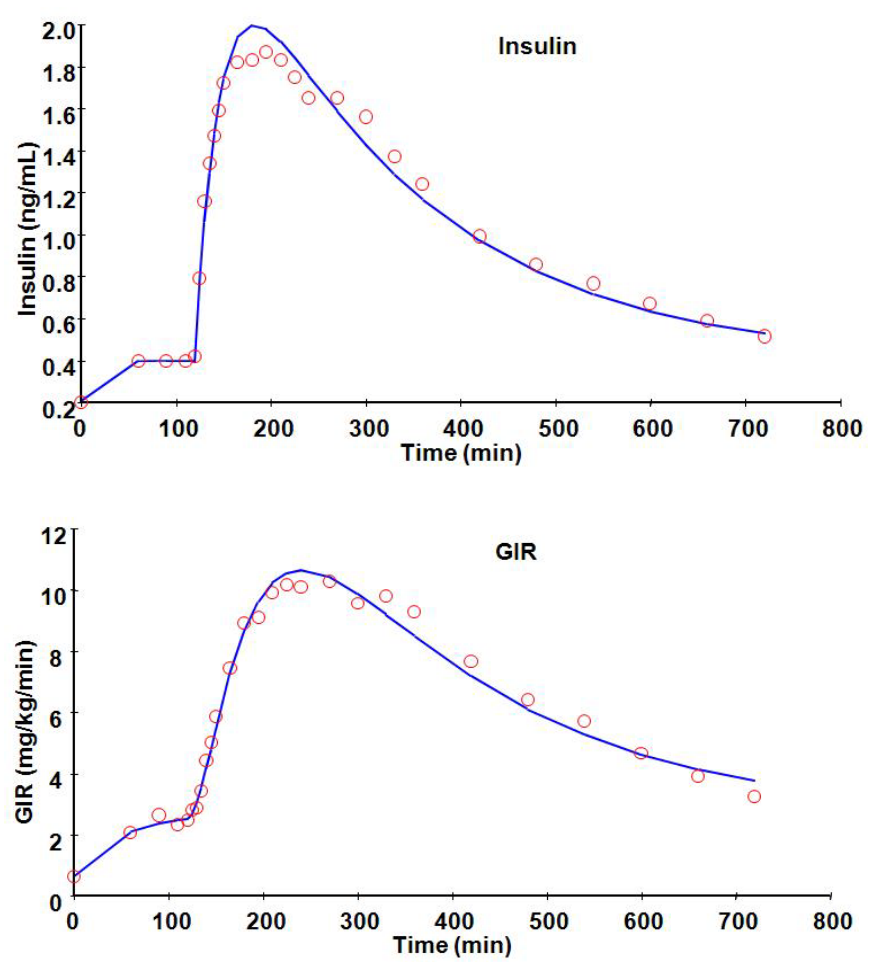

Figure 4: Observed and model predicted serum insulin concentrations and corresponding glucose infusion rate determined during glucose clamp procedures with endogenous insulin suppression via intravenous insulin infusion initiated 120 minutes prior to inhalation or SC injection of RHIIP or Actrapid®, respectively, and continued through the last blood sampling time interval.

\begin{tabular}{|c|c|}
\hline Parameter & RHIIP Value \\
\hline V/F $(\mathrm{mL})$ & 26840 \\
\hline$k_{a}\left(\mathrm{~min}^{-1}\right)$ & 0.00492 \\
\hline$k_{c p}\left(\mathrm{~min}^{-1}\right)$ & 7.38 \\
\hline$k_{p c}\left(\mathrm{~min}^{-1}\right)$ & 512 \\
\hline$k_{e}\left(\mathrm{~min}^{-1}\right)$ & 0.0380 \\
\hline$E_{\text {max }}(\mathrm{mg} / \mathrm{kg} / \mathrm{min})$ & 40.6 \\
\hline$E C_{50}(\mathrm{ng} / \mathrm{mL})$ & 3.06 \\
\hline$k_{\text {in }}(\mathrm{mg} / \mathrm{kg} / \mathrm{min})$ & 0.717 \\
\hline
\end{tabular}

Table 3: Pharmacokinetic and pharmacodynamic parameters obtained using the pharmacokinetic-pharmacodynamic model described in Fig. 1 following inhalation nsulin (RHIIP) administration.

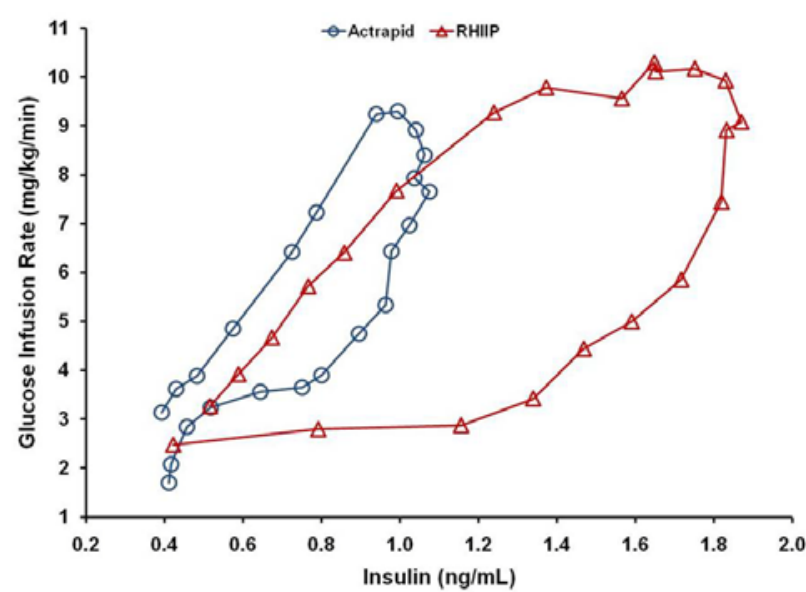

Figure 5: Hysteresis plot for insulin and glucose infusion rate following inhalation of RHIIP or subcutaneous administration of Actrapid $\circledast$.

relationship and potency difference between RHIIP and Actrapid ${ }^{\circledR}$ Furthermore, these results support careful consideration of the dose employed when BP is determined using pharmcodynamic parameters.

\section{Acknowledgment}

The authors would like to thank Ms. Jill Glosson for her excellent technical work in the conduct of the rabbit study.

\section{References}

1. Royle P, Waugh N, McAuley L, Mclntyre L, Thomas S (2006) Inhaled insulin in diabetes mellitus. (Review) The Cochrane Library Issue 1. John Wiley \& Sons, Ltd.

2. Insulin assays in United States Pharmacopoeia, USP 28, 2544, Rockvilee MD. United States Pharmacopoeia Convention, Incorporated, 2007.

3. Design and analysis of biological assays in United States Pharmacopoeia, USP 29, Monograph <111>, Rockville, MD. United States Pharmacopoeia Convention, Incorporated, 2007

4. Clemens AH, Hough DL, D'Orazlo PA (1982) Development of the Biostato Glucose Clamping Algorithm. Clin Chem 28: 1899-1904.

5. Heise T, Brugger A, Cook C, Eckers U, Hutchcraft A, et al. (2009)PROMAXX inhaled insulin: safe and efficacious administration with a commercially available dry powder inhaler. Diabetes Obes MetabDiabetes, Obesity and Metabolism 11: 455-459.

6. D'Argenio DZ, Schuitzky A Wang X (2009) ADAPT 5 User Guide: Pharmacokinetic/Pharmacodynamic Systems Analysis Software. Biomedical Simulations Resource. Los Angeles CA

7. Kim D, Mudaliar S, Chinnapongse S, Chu N, Boies SM, et al. (2003) Doseresponse relationships of inhaled insulin delivered via the Aerodose insulin inhaler and subcutaneously injected insulin in patients with type 2 diabetes. Diabetes CareDiabetes Care 26: 2842-2847.

8. Rave KM, Nosek L, Pena ADL, Seger M, Ernest CS II, et al. (2005) Dose response of inhaled dry-powder insulin and dose equivalence to subcutaneous insulin Lispro. Diabetes Care 28: 2400-2405.

9. Osterberg O, Erichsen L, Ingwersen SH, Plum A, Poulsen HE, et al. (2003) Pharmacokinetic and pharmacodynamic properties of insulin Aspart and human insulin. . J Pharmacokinet Pharmacodyn 30: 221-235.

10. Gopalakrishnan M, Suarez S, Hickey AJ, Gobburu JV (2005) ) Population pharmacokinetic-pharmacodynamic modeling of subcutaneous and pulmonary insulin in rats. . J Pharmacokinet Pharmacodyn 32: 485-500.

11. Landersdorfer CB, Jusko WJ (2010) Pharmacokinetic / pharmacodynamic modeling of glucose clamp effects of inhaled and subcutaneous insulin in healthy volunteers and diabetic patients. Drug Metab Pharmacokinet 25: 418 429 . 